Article

\title{
Resident Perceptions toward Tourism Development at a Large Scale
}

\author{
Rong Li ${ }^{1,2}$, Li Peng ${ }^{1}\left(\mathbb{C}\right.$ and Wei Deng ${ }^{1,2,3, *}$ \\ 1 Research Center for Mountain Development, Institute of Mountain Hazards and Environment, \\ Chinese Academy of Sciences, Chengdu 610041, China; lirong@imde.ac.cn (R.L.); pengli@imde.ac.cn (L.P.) \\ 2 School of Resources and Environment, University of Chinese Academy of Sciences, Beijing 100049, China \\ 3 Chinese Science Center of the International Eurasian Academy of Sciences, Beijing 100107, China \\ * Correspondence: dengwei@imde.ac.cn; Tel.: +86-28-85353897; Fax: +86-28-8535-3897
}

Received: 28 August 2019; Accepted: 15 September 2019; Published: 17 September 2019

\begin{abstract}
Tourism has been experiencing a rapid increase in the developed world, especially in China, and resident perceptions toward tourism development have been receiving increasing attention. However, resident perceptions on a large scale and the associated affecting factors remain unknown. In this study, 63 independent samples across China were analyzed using structural equation modeling, and the effects of three factors of per capita gross domestic product (GDP), tourist receipts and length of tourism development from the perceptive of economy, society and culture, and environment were investigated. Residents demonstrated a positive attitude toward tourism development on a large scale across China. However, the resident perceptions were GDP-dependent, which indicated a lower awareness of infrastructure improvement with the increase in GDP. Meanwhile, residents became more aware of environmental deterioration and social-order disturbance with the increase in the length of tourism development and tourist receipts. In addition, tourist receipts and length of tourism development exerted indirect effects on other perceptions by affecting the perception of environmental deterioration and economic improvement. Our results implied that to minimize the effect of negative perception, attention should be paid to the optimization of the perceptions of economic improvement and environmental deterioration, and the protection of the residential environment should be viewed as a high-priority task in improving resident perceptions.
\end{abstract}

Keywords: tourism; environmental deterioration; economic development; social-cultural perception; structural equation modeling; China

\section{Introduction}

In the context of global sustainable development, tourism, as an environmentally friendly industry, plays an important role in promoting economic development, solving unemployment, and facilitating cultural communication at the destinations [1,2]. Residents at tourist destinations are not only participants in the tourist activities but also stakeholders in the tourism industry. The support of residents for tourism development determines their daily behavior and attitude toward tourists [3]. In addition, resident support for tourism development is related to the sustainable development of destinations [4]. Resident support for tourism development is based on their perceptions of the influences of local tourism [5]. Therefore, investigating the directional changes, degree of change, and influencing factors of resident perception is important.

Residents' perceptions of tourism have attracted great attention. Numerous studies have been conducted in certain areas, and consensus exists that these perceptions fall into three basic categories: perceptions on economy, society and culture, and environment [6,7]. Two different opinions prevail about the influences of tourism development on resident perceptions. In some findings, 
residents perceived that tourism development significantly facilitated local economic development and resident employment [8], and improved society, culture, and local infrastructure construction $[5,9,10]$. However, other studies have noted that residents perceived tourism development had negative effects on the local economy and environment [11-15].

The effects of tourism on resident perceptions have been considered to depend on the economic development condition [16,17], level of tourism development [11,18,19], resident demographic characteristics [6,20,21], and so on. For example, Smith and Krannich [17] demonstrated that residents showed weak perception of negative effects on tourism development in tourism-hungry areas, and maintained contradictory attitudes toward tourism development in tourism-realized areas. Nevertheless, they demonstrated stronger perception of the negative effects of tourism development in tourism-saturated areas [17]. However, current studies that widely collect and analyze data in a single cross-section of time, and investigate the effects of economic development and length of tourism development on the resident perceptions were few and not well understood [12].

The perceptions of residents generally focused on a small scale, and the overall resident perceptions and the associated factors were insufficiently documented on a large scale, although perceptions on a larger scale were believed to be different from that on a smaller scale [4]. Additionally, the relationships among resident perceptions of the economy, society, culture, and environment remain unknown. Few studies have focused on the change directions, key influence factors, and change mechanism of these three perceptions, although resident perceptions have been discussed, along with the resident attitudes and support for tourism development from many publications.

In 2017, the number of tourists in China reached five billion. The comprehensive contribution of the national tourism industry to the gross domestic product (GDP) was RMB 9130 billion, which accounted for $11.04 \%$ of the total GDP. The important role of the tourism industry in China's national economy has become increasingly prominent. Increasing attention was focused on the tourism perceptions of residents, but understanding the change in perceptions of the residents across a large scale in China and its associated factors has been poor and requires more attention. In the present study, studies on resident perception at tourism destinations since 2000 were collected, and the changes and influencing factors of the resident perceptions were analyzed using structural equation modeling (SEM). The present study aims to: (1) Investigate the characteristics of resident perception across China; (2) understand the effects of regional economic development level (per capita GDP), length of tourism development, and tourist receipts on the resident perceptions, and (3) develop correlations among the resident perceptions of the economy, society and culture, and environment.

\section{Methods}

\subsection{Data Collection}

We gathered Chinese and English publications on the perceptions of residents of tourist destinations in China that were published after 2000. The search terms included the keywords "tourism/travel/leisure", "perception/attitude", "residents", and combinations of these terms. Web of Science was used to collect the English articles, and the Chinese articles were sourced from CNKI.com and other major academic databases. Three criteria were applied to the collected articles. First, only full-length academic articles, including empirical case studies of destinations in China were selected, and comments and reviews were excluded. Second, to perform quantitative analysis and obtain other useful data, studies that reported research sites, investigation time, and mean scores of resident perceptions using a five-point Likert scale questionnaire survey and agree/disagree ratio were selected. We extracted the mean scores of the resident perception of the economy, society and culture, and environment from these papers. Third, studies on resident perceptions of tourisms published in non-tourism journals in the selected period were also chosen. Out the total of 52 qualified articles, 12 were in English, and 40 were in Chinese. In addition, 63 independent samples were obtained (Figure S1). These 63 sample sites covered 23 provinces, autonomous regions and municipalities 
directly under the central government of China (Table S1; sample sites with small spatial distances were not repeatedly recorded in the figure).

The research purposes of these 63 existing empirical studies were similar, and we could combine and summarize the same items for residents' perception of tourism effects, which contained positive and negative perception of the economy, society and culture, and environment. According to the previous research and in combination with the actual objective of the present study, the items for resident perception toward tourism in the current work were set up. Table 1 lists a total of 6 categories of 15 items. The six indexes represented the positive and negative perceptions of the economy, society and culture, and environment.

Table 1. Items of resident perception toward tourism development.

\begin{tabular}{|c|c|c|}
\hline Category & Indexes (Abbreviation) & Items \\
\hline \multirow{2}{*}{$\begin{array}{l}\text { Economic } \\
\text { perception }\end{array}$} & $\begin{array}{l}\text { Development of economy and } \\
\text { improvement in living standard } \\
\text { (economic improvement) }\end{array}$ & $\begin{array}{l}\text { Increase economy development } \\
\text { Improve quality of life } \\
\text { Increase employment opportunities }\end{array}$ \\
\hline & $\begin{array}{l}\text { Increase in living cost } \\
\text { (cost increase) }\end{array}$ & $\begin{array}{l}\text { Increase housing cost } \\
\text { Increase price levels }\end{array}$ \\
\hline \multirow{3}{*}{$\begin{array}{l}\text { Social-cultural } \\
\text { perception }\end{array}$} & $\begin{array}{l}\text { Culture protection and } \\
\text { increased influence } \\
\text { (culture protection) }\end{array}$ & $\begin{array}{l}\text { Expand awareness and influence } \\
\text { Promote the development of traditional culture }\end{array}$ \\
\hline & $\begin{array}{l}\text { Disturbance of normal social order } \\
\text { (order disturbance) }\end{array}$ & $\begin{array}{c}\text { Cause more crime and increase alcohol use } \\
\text { Moral decline }\end{array}$ \\
\hline & $\begin{array}{l}\text { Improvement in infrastructure } \\
\text { construction } \\
\text { (infrastructure improvement) }\end{array}$ & $\begin{array}{l}\text { Promote construction in the destination } \\
\text { Improve traffic conditions } \\
\text { Improve infrastructure construction }\end{array}$ \\
\hline $\begin{array}{l}\text { Environmental } \\
\text { perception }\end{array}$ & $\begin{array}{l}\text { Residential environmental } \\
\text { deterioration } \\
\text { (environmental deterioration) }\end{array}$ & $\begin{array}{c}\text { Degrade natural environment } \\
\text { Increase pollution, noise, and water contamination } \\
\text { Increase trash }\end{array}$ \\
\hline
\end{tabular}

All items were measured using a five-point Likert scale based on the following: (1) "strongly disagree" or "very dissatisfied", and (5) "strongly agree" or "very satisfied". The scale respectively indicated "disagree", "neutral", and "agree" when the mean of each observation in each study ranged from 1.0 to 2.4, from 2.5 to 3.4 , and from 3.5 to 5.0. The means of each observation variable in each study were viewed as an independent sample as the original data in the follow-up analysis, because the questionnaire respondents in each paper were independent. We could extract the mean score of the different perception items from the 63 papers. Therefore, our work was equivalent to obtaining 63 independent research samples. In contrast to most existing studies, these 63 samples came from a large scale across China, and they represented the mean scores extracted from other studies.

\subsection{SEM}

SEM can test the direct and indirect effects of two explanatory variables [22]. The net influence of one variable on the other is equal to the total effect, which is estimated by adding all direct and indirect effects of the two variables. In addition, the mutual correlations among different latent variables as well as the effects of each exogenous variable on each latent variable can be explained by SEM.

In this study, the above six indexes (economic improvement, cost increase, culture protection, order disturbance, infrastructure improvement and environmental deterioration) were set as latent variables, which represented the positive and negative perceptions of the residents of the economy (abbreviated as $L_{1}$ and $L_{2}$, respectively), society and culture (abbreviated as $L_{3}$ and $L_{4}$, respectively), and environment (abbreviated as $L_{5}$ and $L_{6}$, respectively). A total of 15 items were used as observation variables to interpret the above six latent variables. Here, their corresponding abbreviations were $O_{11}$, $O_{12}$ and $O_{13}$ (interpreted as $L_{1}$ ), $O_{21}$ and $O_{22}$ (interpreted as $L_{2}$ ), $O_{31}$ and $O_{32}$ (interpreted as $L_{3}$ ), $O_{41}$ and 
$O_{42}$ (interpreted as $L_{4}$ ), $O_{51}, O_{52}$ and $O_{53}$ (interpreted as $L_{5}$ ), and $O_{61}, O_{62}$ and $O_{63}$ (interpreted as $L_{6}$ ) (Table 2). The Cronbach's alpha of all six latent variables was higher than 0.900 , indicating high data consistency. According to the confirmatory factor analysis, the latent variables in the comprehensive measurement model and the corresponding observation variables were input into the prior theoretical model for SEM analysis (Figure 1).

Table 2. List of variable and data reliability values.

\begin{tabular}{|c|c|c|}
\hline Latent Variables & Observation Variables & Cronbach's Alpha \\
\hline $\begin{array}{l}\text { Economic improvement } \\
\qquad\left(L_{1}\right)\end{array}$ & $\begin{array}{l}\text { Increase the development in economy }\left(O_{11}\right) \\
\text { Improve the quality of life }\left(O_{12}\right) \\
\text { Increase employment opportunities }\left(O_{13}\right)\end{array}$ & 0.929 \\
\hline $\begin{array}{l}\text { Cost increase } \\
\quad\left(L_{2}\right)\end{array}$ & $\begin{array}{l}\text { Increase in housing } \operatorname{cost}\left(\mathrm{O}_{21}\right) \\
\text { Increase in price level }\left(\mathrm{O}_{22}\right)\end{array}$ & 0.981 \\
\hline $\begin{array}{l}\text { Culture protection } \\
\left(L_{3}\right)\end{array}$ & $\begin{array}{c}\text { Expand awareness and influence }\left(O_{31}\right) \\
\text { Promote the development of traditional culture }\left(O_{32}\right)\end{array}$ & 0.9 \\
\hline $\begin{array}{l}\text { Order disturbance } \\
\left(L_{4}\right)\end{array}$ & $\begin{array}{l}\text { Cause more crime and increase alcohol consumption }\left(\mathrm{O}_{41}\right) \\
\text { Moral decline }\left(\mathrm{O}_{42}\right)\end{array}$ & 0.984 \\
\hline $\begin{array}{l}\text { Infrastructure improvement } \\
\qquad\left(L_{5}\right)\end{array}$ & $\begin{array}{l}\text { Promote construction in the destination }\left(O_{51}\right) \\
\text { Improve traffic conditions }\left(O_{52}\right) \\
\text { Improve infrastructure construction }\left(O_{52}\right)\end{array}$ & 0.969 \\
\hline $\begin{array}{l}\text { Environmental deterioration } \\
\qquad\left(L_{6}\right)\end{array}$ & $\begin{array}{l}\text { Deteriorate the natural environment }\left(O_{61}\right) \\
\text { Increase noise, and water pollution }\left(O_{62}\right) \\
\text { Increase trash }\left(O_{63}\right)\end{array}$ & 0.937 \\
\hline
\end{tabular}

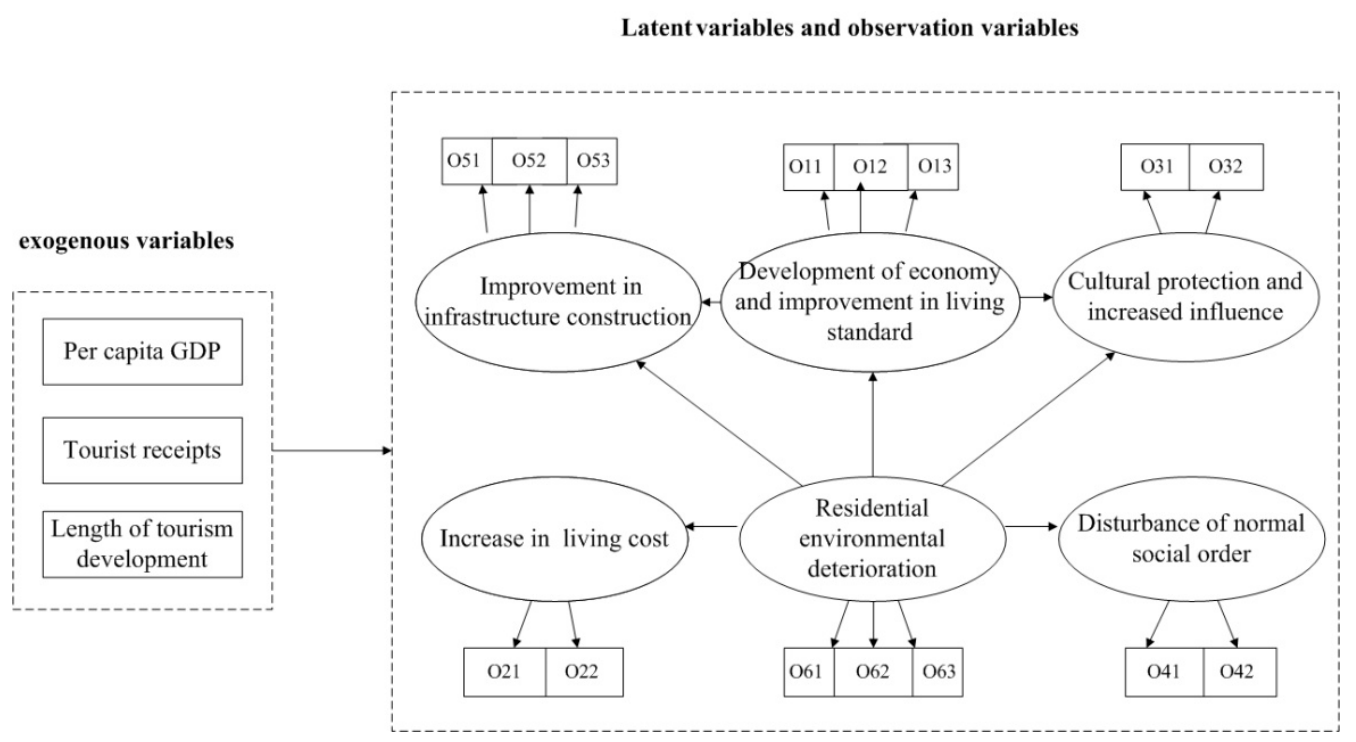

Figure 1. Proposed theoretical model.

The per capita GDP, length of tourism development, and tourist receipts were used as exogenous variables (Figure 1). Acquiring the data on the number of tourists across a large scale is difficult. In this study, the number of comments on the tourists was thus acquired from the Mafengwo website (http://www.mafengwo.cn/), which is the most commonly used tourism network self-service inquiry and sharing platform in China, to express the tourist attention to the destinations. Tourists' attention were used as the approximate tourist receipts, because we found that a strong correlation existed between network attention to tourism and the number of tourists [23,24]. A total of 203,580 comments related to the tourist evaluation of the destinations were collected. The maximum number of online comments in our 63 sampling sites was 35,978, with a minimum of zero. The greater the number of 
comments there was, the higher was the attention to the tourist destination. We standardized the number of comments for subsequent SEM analysis.

\subsection{Theoretical Model and Hypotheses}

A prior model was proposed based on theoretical knowledge and hypotheses (Figure 1) with the following 5 hypotheses:

Economic development significantly influences the perceptions and attitudes of residents [16,17]. In destination regions with relatively poor economic conditions, the strength of resident positive perception of tourism is positively related to their support for tourism $[4,25,26]$. For a large-scale study, the regional per capita GDP was selected to be an economic factor.

Hypothesis 1. Per capita GDP affects the residents' positive and negative perceptions (economic perception, social-cultural perception, and environmental perception).

The regional per capita GDP value in our 63 sampling sites was derived from the data of statistical yearbook and statistical reports, which represented the values in the corresponding years when these studies were conducted.

The level of tourism development was characterized by the density of tourists and cycle of evolution [19,27-29] in some studies. Bestard and Nadal [30] noted that the higher the tourists' density was, the stronger the negative perception of residents on tourism was. In the current study, however, obtaining the data of tourist density and cycle of evolution across a larger scale was difficult, and the level of tourism development could be considered as the length of tourism development and tourist receipts.

Hypothesis 2. Tourist receipts played a significant role in the resident positive and negative perceptions.

Hypothesis 3. The length of tourism development played a significant role in the resident positive and negative perceptions.

In the current study, we searched and collected the length of tourism development in all scenic destinations using the Internet. China's tourism industry has achieved comprehensive development after the reform and opening-up in the 1970s. Therefore, we set the tourism start time of non-scenic tourism destinations, such as Beijing and Dalian cities, to 1978, i.e., the reform and opening-up time.

Generally, residents who perceive a greater level of economic gain tend to have more positive perceptions $[13,31]$. The positive perceptions on the development of the economy and improvement in the living standard, defined as economic improvement, convinced the residents that tourism development positively affects the society and culture, and protects the environment.

Hypothesis 4. The perception of culture protection and infrastructure improvement were dependent on the perception of economic improvement.

The effect of tourism on the environment is also a major concern of residents. When residents are satisfied with the local tourism economic income, they change to pay more attention to the negative influence of tourism development on the environment [25]. Environmental problems caused by tourism can lead to negative perceptions of the local economy, society, and culture $[8,11,32]$.

Hypothesis 5. Negative perception of cost increase and order disturbance were influenced by the perception of environmental deterioration. Additionally, the perception of environmental deterioration had negative effects on infrastructure improvement, economic improvement, and culture protection. 
Outliers and normality were investigated before the SEM analysis, and one outlier was found and excluded from the later SEM analysis, leaving a sample size of 62 . To avoid issues regarding violation of the multivariate normality and obtain confident solutions, the bootstrap resampling method was used. The bootstrap estimator and its associated error were used to determine the significance of the path coefficient and the total effect.

The goodness-of-fit measure includes the $\chi^{2}$ value, $\chi^{2} / d f\left(\chi^{2}\right.$ value/degrees of freedom, the fit is good for $\left.\chi^{2} / d f<3\right)$, comparative fit index (CFI; the fit is good for CFI $\left.>0.95\right)$, root mean square error of approximation (RMSEA; the fit is good or reasonable for RMSEA $<0.05$ or between 0.05 and 0.08 ), and $P_{\text {RMSEA }}$ (the fit is good for $P_{\text {RMSEA }}>0.05$ ) [22]. Data validation was performed using SPSS19.0, and the SEM analyses were performed in AMOS 17.0 in SPSS.

\section{Results}

\subsection{Overall Perception Analysis}

In general, residents demonstrated positive effects of perceptions of tourism development on economic improvement, infrastructure improvement, and culture protection (Table 3). The mean scores of these three perceptions were 3.44,3.89, and 3.68, respectively. Meanwhile, the resident negative perceptions of environmental deterioration, order disturbance, and cost increase demonstrated a neutral attitude with a mean of 2.91,2.72, and 3.29, respectively. These independent samples represented the overall situation in China to a certain extent. These results suggested that on a large scale across China, residents perceived tourism to promote economic development, improve socio-cultural conditions, and protect the environment. In contrast, the negative perceptions were not strong in terms of tourism development to a certain degree.

Table 3. Descriptive statistics.

\begin{tabular}{ccccccc}
\hline Category & Latent Variables & N & Min & Max & Mean & Standard Error \\
\hline Economy & Economic improvement & 63 & 2.41 & 4 & 3.44 & 0.043 \\
perception & Cost increase & 63 & 1.92 & 4.22 & 3.29 & 0.068 \\
Social- cultural & Culture protection & 63 & 3.01 & 4.14 & 3.68 & 0.021 \\
perception & Order disturbance & 63 & 1.51 & 4.78 & 2.72 & 0.073 \\
Environmental & Infrastructure improvement & 63 & 2.4 & 4.64 & 3.89 & 0.049 \\
perception & Environmental deterioration & 63 & 1.5 & 3.75 & 2.91 & 0.051 \\
\hline
\end{tabular}

\subsection{Influences of Exogenous Variables on Latent Variables}

The final SEM could adequately fit the data according to the more robust goodness-of-fit indexes $\left(\chi^{2}=182, d f=160, \chi^{2} / d f=1.14, \mathrm{CFI}=0.983, P_{\mathrm{CFI}}=0.828, \mathrm{RMSEA}=0.048, P_{\mathrm{RMSEA}}=0.526\right)($ Figure 2$)$.

A series of resident perceptions of tourism development was directly related to the length of tourism development. With the increase in the length of tourism development, the residents were less aware of the positive effect, such as infrastructure improvement (direct effect $=-0.2, p<0.05$ ), whereas residents were more aware of the negative effects, such as environmental deterioration and order disturbance (Figure 2). Moreover, the length of tourism development indirectly affected the perceptions of cost increase (indirect effect $=0.093, p=0.011$ ) and order disturbance (indirect effect $=0.098, p=0.007$ ) through the perception of environmental deterioration.

Similar to the length of tourism development, tourist receipts had a significant direct effect on the resident negative perceptions, which was manifested by the negative correlations between the tourist receipts and the perception of environmental deterioration and between the tourist receipts and perception of order disturbance (Figure 2). With the increase in the tourist receipts, residents demonstrated less positive perception, such as economic improvement (Figure 3). In addition, the tourist receipts caused indirect positive effects on perception of cost increase (indirect effect $=0.094$, 
$p=0.013$ ) and order disturbance (indirect effect $=0.098, p=0.007$ ) through the intermediary variable of perception of environmental deterioration. Tourist receipts also caused indirect negative effects on both perception of culture protection (indirect effect $=-0.186, p=0.001$ ) and infrastructure improvement (indirect effect $=-0.133, p=0.007$ ) through the perception of economic improvement (Figure 2).

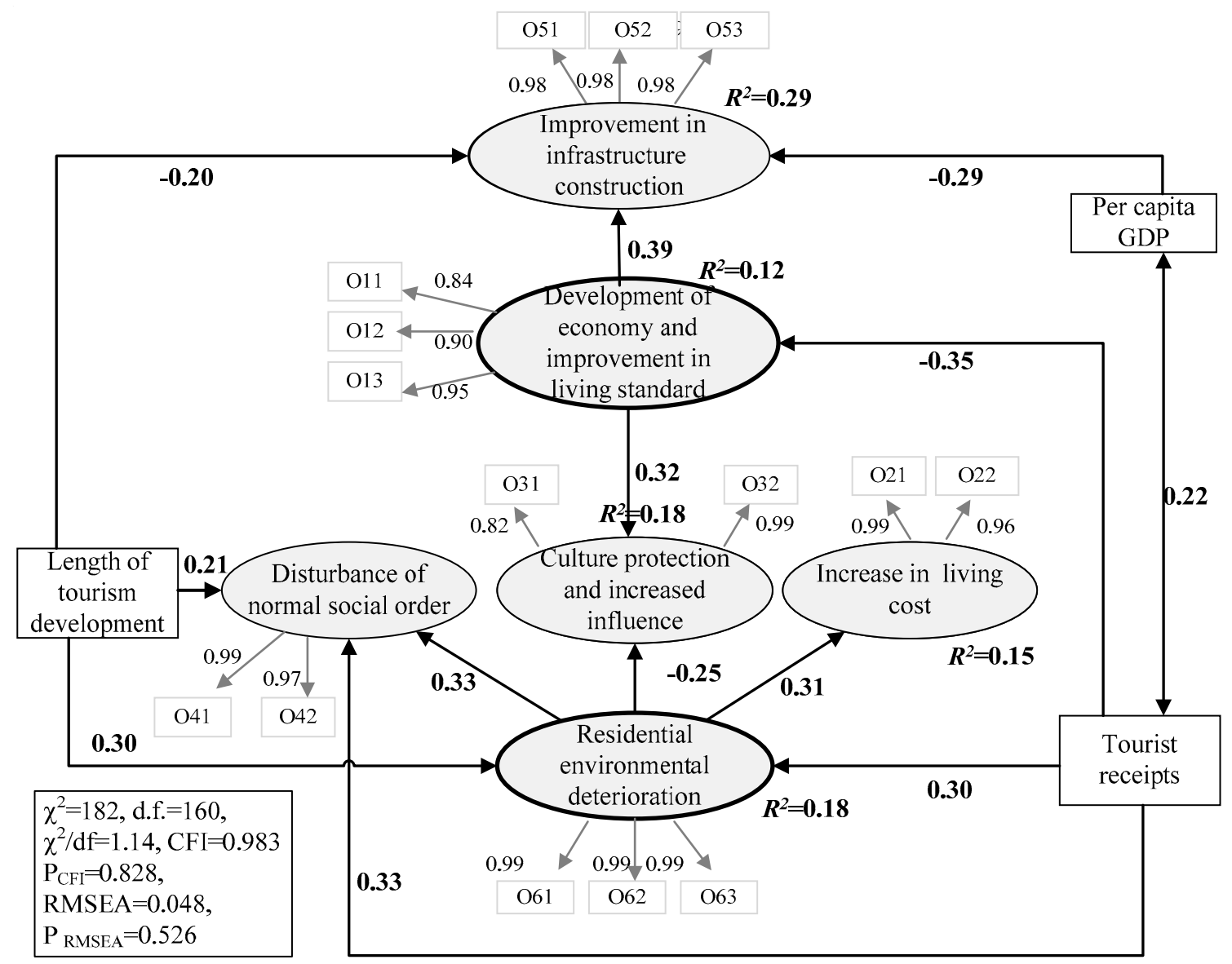

Figure 2. Final structural equation model. The latent variables are presented as ovals, and the observed indicator variables are shown as boxes. Numbers adjacent to the arrows indicate standardized regression coefficients. The explained proportion of variance $\left(\mathrm{R}^{2}\right)$ for each response variable is shown.

The resident perception of infrastructure improvement was negatively related to the GDP, which indicated that when the GDP was higher, residents were more inclined to believe that tourism exerted less effect on the improvement of infrastructure construction. In contrast, in regions with poorer economic conditions, the positive effects of tourism development on the improvement of local infrastructure construction were more likely to be perceived by residents.

To clarify the total effect between two variables, we sum the direct and indirect effects to estimate the net influence. Generally, the total effect of the tourist receipts on the resident negative perceptions, such as the cost increase, order disturbance, and environmental deterioration, were positive, whereas they demonstrate negative total effects on resident positive perceptions, such as economic improvement, culture protection, and infrastructure improvement (Figure 3). The results confirmed hypotheses 2 and 3, with the increase in the tourist receipts, the residents became more aware of the negative effects, and less aware of the significant positive effects. The length of tourism development demonstrated similar effects of tourist receipts on the perceptions, except for a non-significant effect on economic improvement. Though no significant total effect of the GDP on the perceptions was observed (Hypothesis 1), the resident perception of infrastructure improvement was related to the GDP (direct effect $=-0.29$ ). 


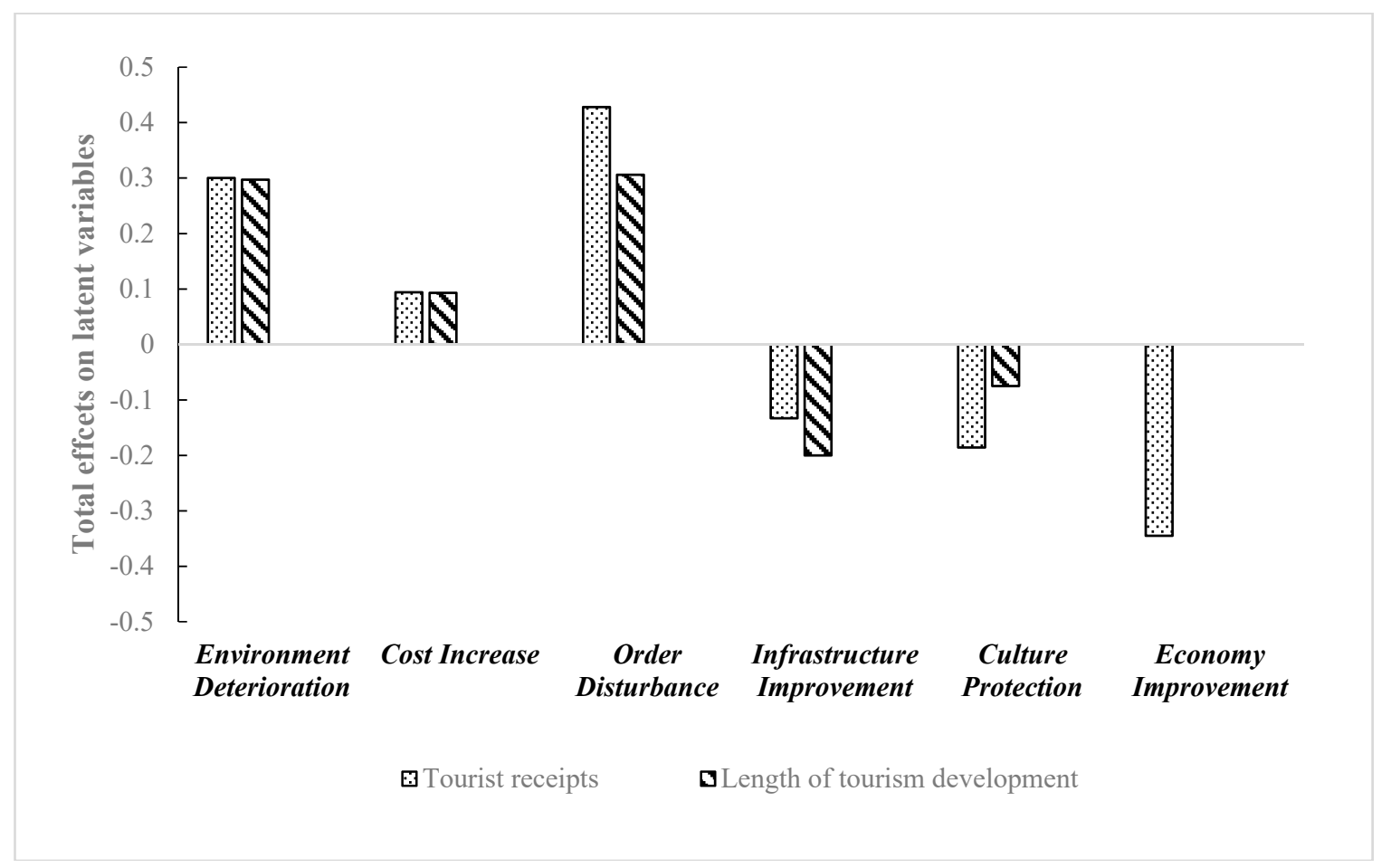

Figure 3. Standardized total effects (sum of the direct and indirect effects) of the exogenous variables on the six latent variables derived by SEM. The two exogenous variables of length of tourism development and tourist receipts show significant effects on the latent variables, whereas gross domestic product (GDP) shows a limited effect. Thus, the GDP variable is not shown.

\subsection{Correlation Analysis of Latent Variables}

Economic improvement directly positively affected infrastructure improvement and culture protection. Additionally, we need to emphasize that with the increase in the resident perception of environmental deterioration, they perceived more negative effects, such as order disturbance and cost increase. Environmental deterioration directly positively affected the order disturbance and cost increase. The reason could be that environmental deterioration strengthened the sensitivity of the residents to the negative effects of tourism development, further making the residents perceive more negative effects on the economy, society, and culture.

\section{Discussion}

\subsection{Perceptions of Tourism Development across China}

On a large scale, we discovered that residents demonstrated strong perceptions of the positive effects of tourism development on economic improvement, infrastructure improvement, and culture protection. The results of this study were consistent with some findings on a local scale, which indicated that residents perceived that tourism could promote economic development, promote cultural exchange, and protect the environment in China. In contrast, residents were less aware of the negative effects of tourism development, such as increased air pollution, water pollution, and increased waste. In general, the resident perceptions of tourism development across China were positive to a certain degree.

\subsection{Effects of GDP, Levels of Tourism Development, and Tourist Receipts on Perceptions}

Liu and Var [25] and Gursoy et al. [4] noted that local economic development conditions can significantly influence the resident perceptions, and residents tend to emphasize the positive effects of tourism but underestimate the negative effects in less-economically developed areas. Similarly, our results also confirm that the resident perception of infrastructure improvement is related to the GDP. 
Construction of infrastructure was shown to benefit more from tourism development in the economic less-economically developed areas, and the positive effect of tourism development on infrastructure improvement was more easily confirmed by residents. Resident perceptions are also related to the tourism development level $[30,33]$. Residents in tourist destinations are considered to generally obtain maximum benefits at lower to moderate levels of tourism development, however, the resident positive perceptions gradually declined with the continuous increase in the tourism level $[30,33]$. Consistently, in the present study, we found that residents perceived more negative effects while perceiving fewer positive effects of tourism development with the increase in tourist receipts. Further, the resident perceptions of negative effects (environment deterioration, order disturbance, and cost increase) became increasingly prominent with the increase in the length of tourism development. This result was supported by the evidence that at the earlier period of tourism development, residents generally agreed that they could gain more benefits than losses from tourism. However, the condition at the later stage was found to be the opposite, and the cognition and perception of the residents also changed [34,35]. Moreover, an increase in the tourist number could result in a series of negative effects on the local environment and economy, including environmental disturbance [21] and an increase in the local service and housing cost. For example, tourism development could significantly improve infrastructure construction, and residents could share these facilities with the tourists at the earlier tourism stage. However, with the increase in tourist receipts, many facilities were occupied by tourists, partially resulting in the increasingly negative perceptions of residents $[5,36]$.

\subsection{Interaction of Resident Perceptions}

The resident perception of economic improvement showed positive effects on the other positive perceptions, whereas resident perception of environmental deterioration intensified the other negative perceptions. In addition, the perceptions of economic improvement and environmental deterioration were found to be intermediate variables between the exogenous and other endogenous variables. Tourist receipts also caused significant indirect negative effects on the perception of culture protection and cost increase both through economic improvement. According to our data from the collected sample cases, the increase in tourist receipts negatively affected the resident perception of economic improvement. In addition, tourist receipts indirectly exerted negative effects on the perception of infrastructure improvement and culture protection through economic improvement and indirectly caused a positive effect on cost increase and order disturbance through the perception of environmental deterioration. These results confirmed hypothesis 4 and hypothesis 5 , that the perception of culture protection and infrastructure improvement were dependent on the perception of economic improvement, and the perception of cost increase and order disturbance were influenced by the perception of environmental deterioration. Additionally, the perception of environmental deterioration had negative effects on infrastructure improvement, economic improvement and culture protection. From our research samples, those with large tourist receipts were mainly concentrated in economically developed cities (e.g., Beijing, Shanghai, and Dalian) and cities with famous scenic areas, whereas destinations with small tourist receipts were mainly concentrated in regions with relatively poor economic development. Hence, with the increase in tourist receipts, residents in economically developed regions did not experience great economic contributions from tourism but were more sensitive to and concerned with the negative effects of tourism development on society, culture, and environment.

This paper provided an insight into the link among resident perceptions of the economy, society, culture, and environment. Quantitative analysis was used to reveal the specific effect paths, including direct and indirect effects. Our results verified the important roles of perception of economic improvement and environmental deterioration in the proposed research framework. First, they directly influenced other latent variables in the model. These two variables were the key to determining other perception types in the overall framework. Second, the perceptions of economic improvement and environmental deterioration bridged the exogenous (tourist receipts and length of 
tourism development) and latent variables. The length of tourism development and tourist receipts indirectly caused negative effects on other positive perceptions through the perception of economic improvement and indirectly exerted positive effects on the other negative perceptions through the perception of environmental deterioration. These conclusions are innovative conclusions in the study of resident tourism perception in recent years, which opens up a new perspective for the study of resident tourism perception in the future.

These results indicated that attention must be paid to protect the living conditions of residents in tourism areas, so as to change their negative environmental perception toward tourism development. In addition, we suggest a strengthening of the role of tourism economy in local economic development and increasing the resident understanding of the positive effects of tourism in the development of the economy and improvement in the quality of life. In summary, to achieve sustainable development of the tourism industry, the important role of tourism in promoting resident employment and improving their living standard by protecting their survival and their living conditions must be emphasized.

Although this paper provided an insight into the resident perceptions of the economy, society, culture, and environment, it still has several limitations. These limitations should be discussed to provide guidance for future research. Firstly, due to the complexity of the relevant literature collection, collation, and data analysis processes involved in this study, 63 sample sites covering 23 provinces, autonomous regions, and municipalities directly under the central government of China were collected, and the responding research time was after 2000. Further, more samples should be collected so as to extend the time and space sequence of related research. Secondly, in the current study, the length of tourism development and tourist receipts were used to represent the level of tourism development in tourism destinations. However, it might not be enough to illustrate the actual context of each of those destinations. So, future research may consider additional factors, such as different types of tourism destinations and tourism consumption per person. Additionally, resident perceptions of tourism impacts may change with their personal economic gain and direct or indirect involvement with tourism. Further research should explore the model proposed and select appropriate factors to represent residents' participation in tourism on a large scale in China.

\section{Conclusions}

Generally, residents in tourist destinations demonstrate positive attitudes toward tourism development across China. It was believed that tourism facilitates local economic development, promotes culture protection, and improves infrastructure construction. Tourism brings mild negative effects. However, with the increase in the tourist receipts and length of tourism development, residents begin to perceive more negative effects. They became more sensitive to negative influences, such as the ruining of environment, increased social disorder, and increased cost of living. Additionally, the perception of economic improvement and environmental deterioration were found to play a central role in affecting other perceptions. Therefore, attention should be paid to optimize the perceptions of economic improvement and environmental damage, and protection of the residential environment should be viewed as a high-priority task to improve resident perceptions. Based on major research conclusions, specific suggestions are as follows:

(1) Policy support, tourism development mode optimization, and improvement of tourism management should be based on increasing the tourism participation of residents, increasing the direct or indirect tourism revenues of residents, protecting residents' benefits from tourism development, and making residents be aware of the perception of the positive economic effects of tourism development;

(2) Environmental protection should be prioritized in destinations and initiative should be taken to maintain the residential environment. Efforts should be made to enhance propagation education, and increase the environmental protection awareness of tourists. At the same time, the supervision mechanism should be strengthened;

(3) It is recommended that tourist receipts be strictly controlled according to environmental capacity and to reduce the negative effects of tourist oversaturation on the local environment. It was 
reported on the website of Spanish Daily Public on August 5th, 2018, that protests and demonstrations against tourist oversaturation had overwhelmed many cities in southern Europe, where the excessive growth of tourism has significantly influenced the lifestyle, social welfare, and access to services and commodities of local residents. Therefore, we recommend adopting effective measures to positively control the number of tourists.

Supplementary Materials: The following are available online at http://www.mdpi.com/2071-1050/11/18/5074/s1, Figure S1: Spatial distribution of the study sites, Table S1: Site characteristics for the residents' perceptions studies.

Author Contributions: Conceptualization, R.L., L.P., and W.D.; methodology, R.L.; formal analysis, R.L.; data curation, R.L.; writing—original draft preparation, R.L.; writing—review and editing, R.L., L.P., and W.D.; visualization, R.L.

Funding: This research was funded by the Science and Technology Service Network Initiative (STS program, No. KFJ-STS-QYZD-060), and the National Natural Science Foundation of China (Grant NO.41771194).

Acknowledgments: The authors would like to thank the anonymous reviewers for their comments on improving of this paper.

Conflicts of Interest: The authors declare no conflict of interest.

\section{References}

1. Zhang, J.Y.; Inbakaran, R.J.; Jackson, M.S. Understanding community attitudes towards tourism and host-guest interaction in the urban-rural border region. Tour. Geogr. 2006, 8, 182-204. [CrossRef]

2. Force, A.; Manuel-Navarrete, D.; Benessaiah, K. Tourism and transitions toward sustainability: Developing tourists' pro-sustainability agency. Sustain. Sci. 2017, 2, 1-15. [CrossRef]

3. Fridgen, J.D. Dimensions of Tourism; Ah \& Ma Educational Institute: East Lansing, MI, USA, 1990.

4. Gursoy, D.; Jurowski, C.; Uysal, M. Resident attitudes: A structural modeling approach. Ann. Tour. Res. 2002, 29, 79-105. [CrossRef]

5. Andereck, K.L.; Valentine, K.M.; Knopf, R.C.; Vogt, C.A. Residents' perceptions of community tourism impacts. Ann. Tour. Res. 2005, 32, 1056-1076. [CrossRef]

6. Almeidagarcía, F.; Peláezfernández, M.Á.; Balbuenavázquez, A.; Cortésmacias, R. Residents' perceptions of tourism development in Benalmádena (Spain). Tour. Manag. 2016, 54, 259-274. [CrossRef]

7. Gursoy, D.; Chen, J.; Yoon, Y. Using Structural Equation Modeling to Assess the Effects of Tourism Impact Factors and Local Residents Support for Tourism Development. In Proceedings of the Annual Conference Proceedings of the Travel and Tourism Research Association, Burbank, CA, USA, 11-14 June 2000; pp. $243-250$.

8. Andereck, K.L.; Nyaupane, G.P. Exploring the Nature of Tourism and Quality of Life Perceptions among Residents. J. Travel Res. 2010, 50, 248-260. [CrossRef]

9. Oviedo-Garcia, M.A.; Castellanos-Verdugo, M.; Martin-Ruiz, D. Gaining residents' support for tourism and planning. Int. J. Tour. Res. 2010, 10, 95-109. [CrossRef]

10. Rezaei, N. Resident perceptions toward tourism impacts in historic center of Yazd, Iran. Tour. Geogr. 2017, 3, 1-22. [CrossRef]

11. Diedrich, A.; Garcíabuades, E. Local perceptions of tourism as indicators of destination decline. Tour. Manag. 2009, 30, 512-521. [CrossRef]

12. Sharpley, R. Host perceptions of tourism: A review of the research. Tour. Manag. 2014, 42, 37-49. [CrossRef]

13. Mcgehee, N.G.; Andereck, K.L. Factors predicting rural residents' support of tourism. J. Travel Res. 2004, 43, 131-140. [CrossRef]

14. Stylidis, D. Place Attachment, Perception of Place and Residents' Support for Tourism Development. Tour. Plan. Dev. 2018, 1, 1-23. [CrossRef]

15. Camisani, P.B. Sri Lanka: A political ecology of socio-environmental conflicts and development projects. Sustain. Sci. 2018, 13, 1-15. [CrossRef]

16. Lepp, A. Tourism and dependency: An analysis of Bigodi village, Uganda. Tour. Manag. 2008, 29, $1206-1214$. [CrossRef]

17. Smith, M.D.; Krannich, R.S. Tourism dependence and resident attitudes. Ann. Tour. Res. 1998, 25, 783-802. [CrossRef] 
18. Allen, L.R.; Long, P.T.; Perdue, R.R.; Kieselbach, S. The impact of tourism development on residents' perceptions of community life. J. Travel Res. 1988, 27, 16-21. [CrossRef]

19. Long, P.T.; Perdue, R.R.; Allen, L. Rural resident tourism perceptions and attitudes by community level of tourism. J. Travel Res. 2016, 28, 3-9. [CrossRef]

20. Nunkoo, R.; Gursoy, D. Residents' support for tourism: An identity perspective. Ann. Tour. Res. 2012, 39, 243-268. [CrossRef]

21. Kuvan, Y.; Akan, P. Residents' attitudes toward general and forest-related impacts of tourism: The case of Belek, Antalya. Tour. Manag. 2005, 26, 691-706. [CrossRef]

22. Kline, R.B. Principles and Practice of Structural Equation Modeling; Guilford Publications: New York, NY, USA, 2011; p. 101.

23. Wang, S.; Zeng, K.F.; Tong, J.; Liu, C. A Correlative Analysis of the Relationship between Tourists and Tourist Network Attention for Scenic Spots in Special Session. Econ. Geogr. 2013, 33, 182-186.

24. Li-Jun, M.A.; Sun, G.N.; Huang, Y.M.; Zhou, R.N. A Correlative Analysis on the Relationship between Domestic Tourists and Network Attention. Econ. Geogr. 2011, 31, 680-685.

25. Liu, J.C.; Var, T. Resident attitudes toward tourism impacts in Hawaii. Ann. Tour. Res. 1986, 13, $193-214$. [CrossRef]

26. Perdue, R.R.; Long, P.T.; Allen, L. Resident support for tourism development. Ann. Tour. Res. 1990, 17, 586-599. [CrossRef]

27. Látková, P.; Vogt, C.A. Residents' attitudes toward existing and future tourism development in rural communities. J. Travel Res. 2012, 51, 50-67. [CrossRef]

28. Brida, J.G.; Osti, L.; Faccioli, M. Residents' perception and attitudes towards tourism impacts: A case study of the small rural community of Folgaria (Trentino-Italy). Soc. Sci. Electron. Publ. 2011, 18, 325-328.

29. Vargassánchez, A.; Porrasbueno, N.; Plazamejía, M.D.Á. Residents' attitude to tourism and seasonality. J. Travel Res. 2014, 53, 581-596. [CrossRef]

30. Bujosa Bestard, A.; Rossellónadal, J. Modelling environmental attitudes toward tourism. Tour. Manag. 2007, 28, 688-695. [CrossRef]

31. Rasoolimanesh, S.M.; Ringle, C.M.; Jaafar, M.; Ramayah, T. Urban vs. rural destinations: Residents' perceptions, community participation and support for tourism development. Tour. Manag. 2017, 60, 147-158. [CrossRef]

32. Krippendorf, J. Towards new tourism policies: The importance of environmental and sociocultural factors. Tour. Manag. 1982, 3, 135-148. [CrossRef]

33. Haley, A.J.; Snaith, T.; Miller, G. The social impacts of tourism a case study of Bath, UK. Ann. Tour. Res. 2005, 32, 647-668. [CrossRef]

34. Moscardo, G.; Pearce, P.L.; Ross, G.F. Tourism Community Relationships; Elsevier Limited: Amsterdam, The Netherlands, 1996.

35. Tosun, C. Expected nature of community participation in tourism development. Tour. Manag. 2006, 27, 493-504. [CrossRef]

36. Chi, G.Q.; Cai, R.; Li, Y. Factors influencing residents' subjective well-being at World Heritage Sites. Tour. Manag. 2017, 63, 209-222. [CrossRef]

(C) 2019 by the authors. Licensee MDPI, Basel, Switzerland. This article is an open access article distributed under the terms and conditions of the Creative Commons Attribution (CC BY) license (http://creativecommons.org/licenses/by/4.0/). 